DOI: https://doi.org/10.31849/bidik.v1i2.5702

\title{
Peningkatan Kemampuan Manajemen Perpustakaan Berbasis Inklusi Sosial pada Pengelola Perpustakaan Desa di Ponorogo
}

\author{
Meinia Prasyesti*, Koko Srimulyo**, Rahma Sugihartati***, \\ Hendro Margono, dan Helmy Prasetyo. \\ Fakultas Ilmu Sosial dan Ilmu Politik, Universitas Airlangga Surabaya \\ *Email: meiniaprasyesti@,fisip.unair.ac.id
}

\begin{abstract}
Library transformation based on social inclusion is one of the priority policies initiated by the central government. This program is intended to improve the welfare of the community by strengthening literacy. The village library as a source of information is expected to be able actively participate in strengthening literacy. Partners in this Community Service activity are the Manuk Village Library, Siman District, Ponorogo Regency East Java. The purpose of this activity is to improve the ability of village librarian regarding social inclusion-based village library management. The training materials include optimizing the role and function of libraries in increasing literacy for welfare, planning participatory activities that involve the community in increasing literacy for welfare, and making guidelines for evaluating the performance of village libraries in order to realize social inclusion-based village libraries. In addition, FGD was also conducted to explore the problems faced by village librarian and formulate strategies to solve these problems. Participants who took part in this training were 15 village librarian. After the implementation of this activity, all participants expressed their enthusiasm for managing the village library according to the material given. This activity is expected to be carried out in a sustainable manner and it is necessary to evaluate activities so that in the future it can arrange activities are better and more useful.
\end{abstract}

Keywords: Library Management, Village Library, Social Inclusion, and Librarian.

\begin{abstract}
Abstrak
Transformasi perpustakaan berbasis inklusi sosial merupakan salah satu kebijakan prioritas yang digagas Pemerintah pusat. Program ini dimaksudkan dapat meningkatkan kesejahteraan masyarakat dengan cara penguatan literasi. Perpustakaan desa sebagai salah satu sumber informasi masyarakat diharapkan dapat berperan serta secara aktif dalam penguatan literasi tersebut. Mitra dalam kegiatan Pengabdian kepada Masyarakat ini adalah Perpustakaan Desa Manuk, Kecamatan Siman, Kabupaten Ponorogo - Jawa Timur. Tujuan dari kegiatan ini adalah meningkatkan kemampuan pengelola perpustakaan desa tentang manajemen perpustakaan desa berbasis inklusi sosial. Materi pelatihan meliputi pengoptimalan peran dan fungsi perpustakaan dalam peningkatan literasi untuk kesejahteraan, perencanaan kegiatan partisipatif yang melibatkan masyarakat dalam meningkatkan literasi untuk kesejahteraan, dan membuat pedoman evaluasi kinerja perpustakaan desa dalam rangka mewujudkan perpustakaan desa berbasis inklusi sosial. Selain itu juga dilakukan FGD untuk menggali permasalahan yang dihadapi para pengelola perpustakaan desa serta merumuskan strategi sebagai langkah alternatif menyelesaikan permasalahan tersebut. Peserta yang mengikuti pelatihan ini sebanyak 15 pengelola perpustakaan desa. Setelah dilaksanakannya kegiatan ini dapat diketahui bahwa seluruh peserta menyatakan bersemangat untuk mengelola perpustakaan desa sesuai materi yang telah diberikan. Dengan demikian kegiatan ini diharapkan dapat dilaksanakan berkelanjutan serta perlu dilakukan evaluasi
\end{abstract}


kegiatan agar ke depan dapat menyusun kegiatan Pengabdian kepada Masyarakat yang lebih baik dan bermanfaat.

Kata Kunci: Manajemen Perpustakaan, Perpustakaan Desa, Inklusi Sosial, Pengelola Perpustakaan.

\section{Pendahuluan}

Transformasi perpustakaan berbasis inklusi sosial merupakan salah satu kebijakan prioritas yang digagas Pemerintah pusat melalui BAPPENAS dan Perpustakaan Nasional RI, yaitu dengan sasaran utama adalah perpustakaan desa di seluruh Kabupaten/Kota di Indonesia (Bondar, 2019). Program ini dimaksudkan dapat meningkatkan kesejahteraan masyarakat, khususnya masyarakat di daerah pedesaan dengan cara penguatan literasi. Perpustakaan desa sebagai salah satu sumber informasi masyarakat diharapkan dapat berperan serta secara aktif dalam penguatan literasi tersebut. Selain menyediakan berbagai jenis koleksi perpustakaan yang sesuai dengan kebutuhan masyarakat, perpustakaan desa juga dapat menjadi tempat belajar bersama, berdiskusi, berjejaring, serta mengadakan program-program khusus yang dapat meningkatkan pemberdayaan masyarakat. Misalnya, pelatihan membuat kerajinan tangan kekinian yang berpotensi dipasarkan, mengadakan workshop tentang pertanian, peternakan, atau bisnis digital, dan pelatihan lain yang disesuaikan dengan kebutuhan dan kondisi masyarakat setempat. Sehingga masyarakat akan memiliki pengetahuan yang cukup, ketrampilan (softskill) yang memadai, untuk menunjang pemberdayaan ekonomi menuju kesejahteraan.

Mitra dalam kegiatan Pengabdian kepada Masyarakat ini adalah Perpustakaan Desa Manuk, Kecamatan Siman, Kabupaten Ponorogo - Jawa Timur. Dimana perpustakaan desa memainkan peranan penting dalam program transformasi perpustakaan berbasis inklusi sosial. Perlu sumber daya manusia (pustakawan) yang handal dalam mengelola perpustakaan desa untuk dapat mencapai tujuan di atas. Namun faktanya, perpustakaan desa sebagai perpustakaan umum yang menjadi kewajiban pemerintah desa belum dikelola secara professional (Alam, 2015). Mayoritas pengelola perpustakaan desa adalah perangkat desa yang ditugaskan bekerja di perpustakaan secara bergantian. Hal demikian juga terjadi di Perpustakaan Desa Manuk Kecamatan Siman Kabupaten Ponorogo. Menurut informasi dari Kepala Desa setempat, perpustakaan yang terletak di tengah kantor desa ini dikelola oleh beberapa perangkat desa secara bergantian dan sukarela. Berlandaskan hal tersebut perlu dilakukan adanya suatu pelatihan dalam mengelola Perpustakaan Desa berbasis Inklusi Sosial melalui kegiatan Pengabdian kepada Masyarakat. 


\section{Gambar 1. Kondisi Layanan Perpustakaan Mitra}

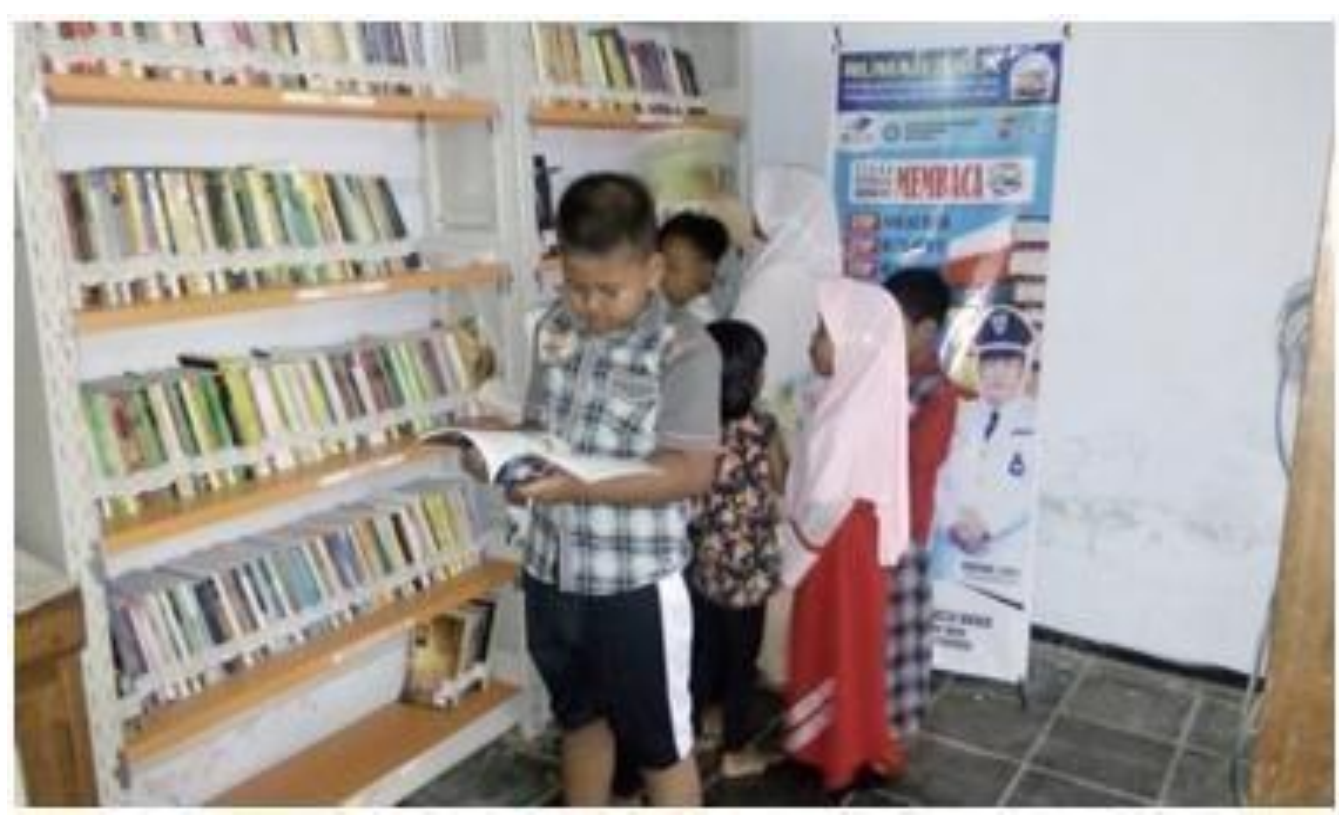

Kegiatan Pengabdian kepada Masyarakat yang dilakukan ini adalah dalam rangka memberikan pelatihan kepada Perangkat Desa Manuk Kecamatan Siman Kabupaten Ponorogo yang dengan sukarela mengelola Perpustakaan Desa, pelatihan yang dimaksud adalah tentang Manejemen Perpustakaan Berbasis Inklusi Sosial. Dengan program pengabdian masyarakat ini diharapkan peningkatan pengetahuan dan skill managerial akan sangat membantu para pengelola perpustakaan untuk menjalankan dan mensukseskan program transformasi perpustakaan di Indonesia.

Mencermati Permendagri RI Nomor 7 Tahun 2007, pemberdayaan masyarakat merupakan suatu strategi dalam pembangunan masyarakat untuk mewujudkan kemampuan dan kemandirian kehidupan bermasyarakat, berbangsa dan bernegara. Pemberdayaan masyarakat dapat dikatakan berhasil apabila proses memandirikan masyarakat dapat terwujud. Tujuan pemberdayaan masyarakat adalah membentuk individu dan masyarakat menjadi mandiri dalam memecahkan masalah yang dihadapi. Kemandirian meliputi kemandirian berpikir, bertindak, dan mengendalikan apa yang mereka lakukan yang diperoleh melalui proses belajar. Oleh karena itu, di tengah-tengah masyarakat perlu dihadirkan pusat-pusat kegiatan belajar masyarakat untuk memfasilitasi berbagai kegiatan pemberdayaan bagi masyarakat (Utami \& Prasetyo, 2019).

Perpustakaan desa memiliki fungsi yaitu sebagai unit pelayanan publik yang menyediakan layanan informasi agar dapat diakses dan dikunjungi oleh seluruh lapisan masyarakat, dengan tidak membedakan status sosial ekonomi, gender, maupun usianya. Namun untuk menjalankan program transformasi perpustakaan, perpustakaan desa perlu melangkah lebih jauh yaitu menjalankan peran fasilitator kegiatan pelibatan masyarakat dengan tujuan agar mereka belajar dan berkegiatan guna mencapai kesejahteraan (Irsan, 2019). Dalam hal ini bentuk pembelajaran, pelatihan dan aktivitas produktif dapat digagas oleh perpustakaan agar perpustakaan desa tidak saja menjadi lembaga penyedia koleksi dan informasi tetapi ikut andil dalam memotivasi 
masyarakat dalam mengembangkan kesejahteraan di bidang sosial, budaya dan ekonomi. Hasil dari aktivitas pembelajaran, pelatihan dan produktif diharapkan memberikan dampak bagi masyarakat dalam meningkatkan taraf kehidupan. Bertitik tolak dari permasalahan dan tujuan seperti dipaparkan di atas, ke depan perpustakaan desa perlu menjalankan manajemen pengelolaan perpustakaan desa yang terencana dan strategis yang berorientasi pada aktivitas pembelajaran, pelatihan dan kegiatan produktif diharapkan memberikan dampak bagi masyarakat dalam meningkatkan taraf kehidupan. Dalam perpustakaan desa diperlukan pengelola yang paham manajemen perpustakaan dan mempunyai kompetensi managerial yang tidak saja sekedar berkaitan dengan penyediaan koleksi dan informasi yang dibutuhkan masyarakat desa, tetapi menggagas manajemen perpustakaan yang mendorong kegiatan produktif yang berdampak secara sosial, budaya maupun finansial bagi masyarakat.

\section{Pendekatan Pelaksanaan Program}

Kegiatan Pengabdian ini pada dasarnya bertujuan untuk membantu peningkatan kompetensi para pengelola perpustakaan desa, terutama di bidang manajemen pengelolaan perpustakaan yang lebih sesuai dengan kebutuhan pergeseran peran dan pengembangan perpustakaan berbasis inklusi sosial. Peserta dalam kegiatan Pengabdian kepada Masyarakat ini adalah 15 orang Pengelola Perpustakaan Desa Manuk Kecamatan Siman Kabupaten Ponorogo Jawa Timur.

\section{Gambar 2. Pembukaan Acara Pengabdian kepada Masyarakat}

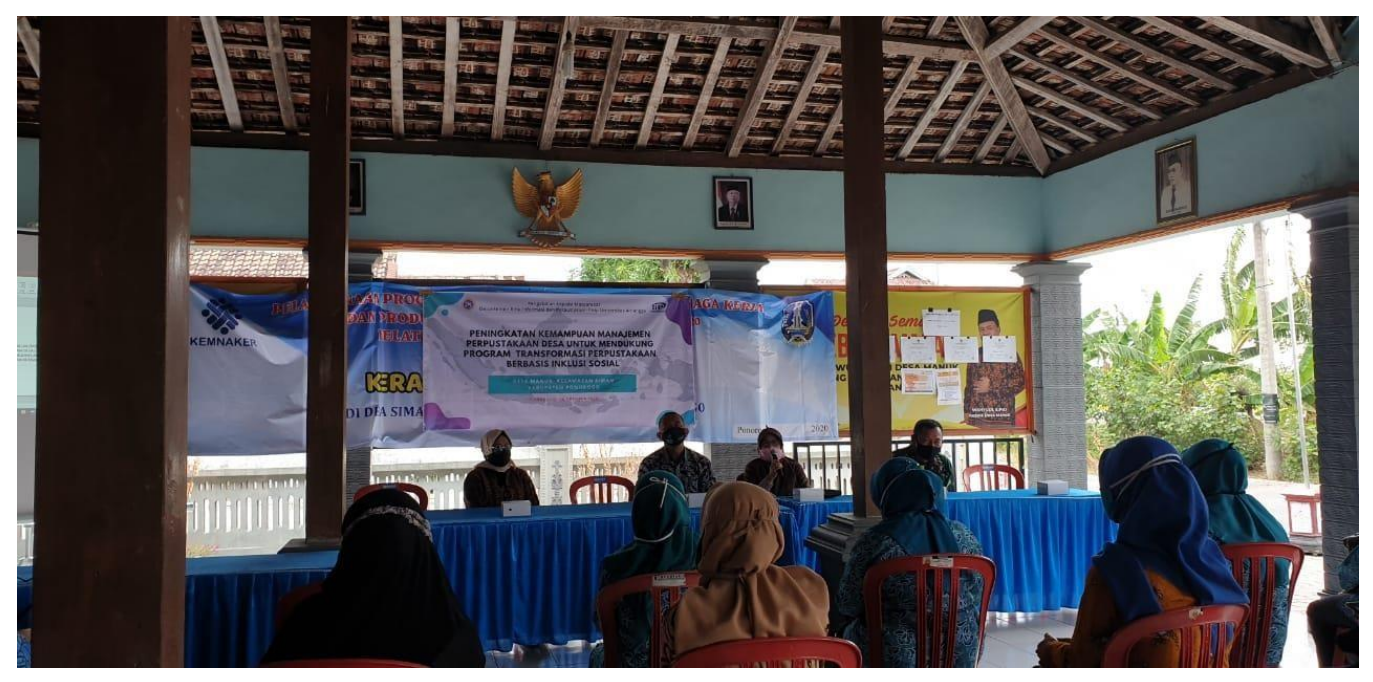

Dalam kegiatan pengabdian kepada masyararakat ini meliputi dua kegiatan utama yaitu, (1) pemberian materi tentang manajemen perpustakaan berbasis inklusi sosial, oleh dosen Ilmu Informasi dan Perpustakaan FISIP Universitas Airlangga yang mendalami bidang manajemen perpustakaan, materi meliputi pengoptimalan peran dan fungsi perpustakaan dalam peningkatan literasi untuk kesejahteraan, perencanaan kegiatan-kegiatan partisipatif yang melibatkan masyarakat dalam meningkatkan literasi untuk kesejahteraan, dan membuat pedoman evaluasi kinerja perpustakaan desa dalam rangka mewujudkan perpustakaan desa berbasis inklusi sosial; (2) melakukan Focus Group Discussion (FGD) untuk menggali permasalahan yang dihadapi para pengelola perpustakaan desa dalam memberikan layanan perpustakaan serta merumuskan strategi 
sebagai langkah alternatif menyelesaikan permasalahan tersebut. Dalam FGD tersebut didampingi beberapa fasilitator. Kegiatan ini berjalan sangat baik dengan antusias dari peserta yang sangat tinggi. Hal ini terlihat dari banyaknya peserta yang bertanya, saling bertukar pendapat, serta memberi saran dan masukan dalam pengelolaan perpustakaan desa. Dengan demikian kami berkesimpulan bahwa materi yang disampaikan telah memberikan pengetahuan baru bagi para peserta (pengelola perpustakaan desa).

\section{Gambar 3. Kegiatan Penyampaian Materi}

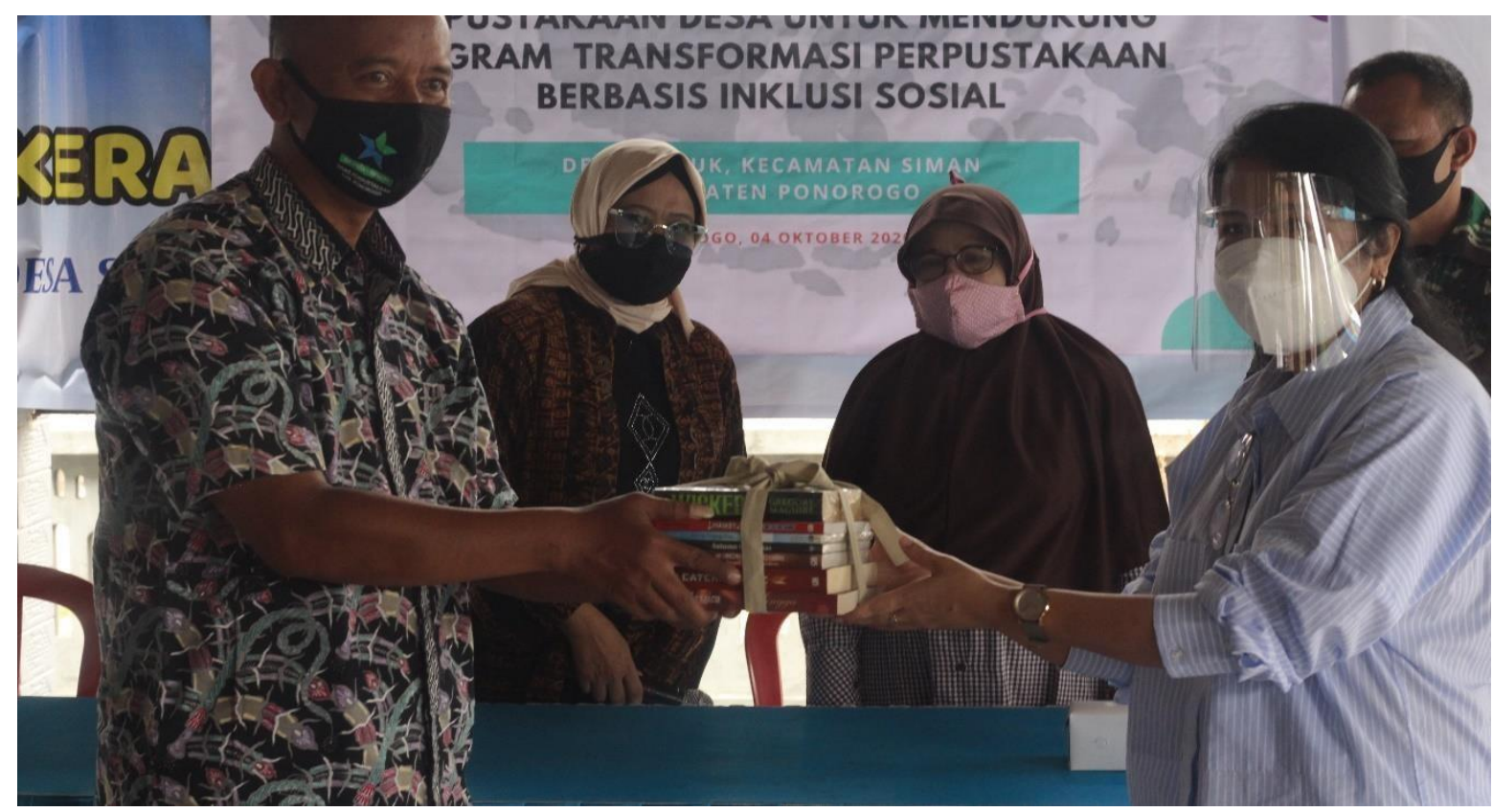

Gambar 4. Penyerahan sumbangan buku secara simbolis

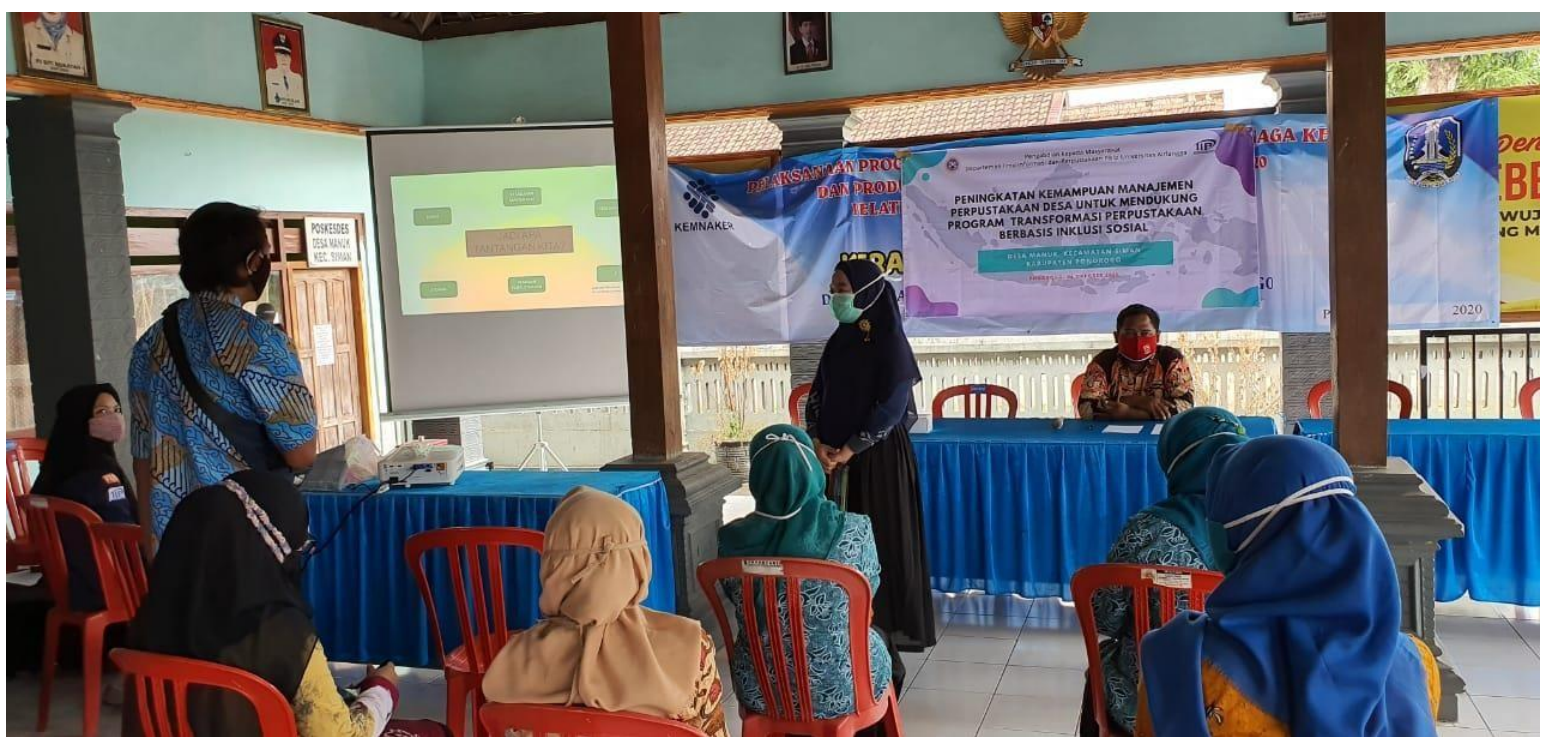

Diakhir kegiatan tim pengabdian kepada masyarakat Departemen Informasi dan Perpustakaan juga memberikan sumbangan buku yang terdiri dari novel, komik, buku tentang pertanian, peternakan, kerajinan tangan, wirausaha dan bacaan lainnya kepada Perpustakaan Desa Manuk Kabupaten Ponorogo. Hal ini dimaksudkan selain untuk menambah koleksi perpustakaan 
desa, bahan bacaan yang disumbangkan tersebut mampu menjadi daya tarik tersendiri bagi masyarakat agar mau berkunjung ke perpustakaan desa, memanfaatkan bacaan yang ada, sehingga dapat menambah pengetahuan baru bagi masyarakat. Dari pengetahuan ini diharapkan masyarakat akan lebih produktif khususnya dalam bidang ekonomi, sehingga dapat menjadikan masyarakat desa lebih berdaya dan sejahtera melalui perpustakaan desa.

\section{Refleksi Capaian Program}

Kegiatan pengabdian masyarakat yang dilaksanakan oleh Departemen Informasi dan Perpustakaan FISIP Unair bertajuk "Peningkatan Kemampuan Manajemen Perpustakaan Desa untuk Mendukung Program Transformasi Perpustakaan Berbasis Inklusi Sosial" dapat terselenggara dengan baik dan memberikan sumbagsih pengetahuan baru bagi pengelola perpustakaan desa. Hal ini terlihat dari hasil pretest yakni sebesar $85 \%$ peserta belum mengetahui program transformasi perpustakaan desa berbasis inklusi sosial, setelah mengikuti kegiatan ini melalui hasil post tes sebesar 95\% peserta menyatakan telah mendapat pengetahuan baru tentang manajemen perpustakaan desa berbasis inklusi sosial. Selain itu data post tes menunjukan bahwa $100 \%$ peserta merasa bersemangat untuk mengelola perpustakaan desa sesuai materi yang telah diberikan. Dengan demikian kegiatan Pengabdian kepada Masyarakat ini perlu diagendakan sebagai kegiatan yang berkelanjutan agar memperoleh pengetahuan bagaimana cara meningkatkan kompetensi pengelolaan perpustakaan berbasis inklusi sosial secara komprehensif.

\section{Penutup}

Berdasarkan pemaparan pelaksanaan Kegiatan Pengabdian kepada Masyarakat di atas, bahwa kegiatan semacam ini telah memberikan dampak yang cukup positif kepada masyarakat terutama pada mitra kegiatan. Oleh sebab itu kegiatan ini diharapkan dapat dilaksanakan berkelanjutan pada tahun - tahun berikutnya. Serta perlu dilakukan evaluasi kegiatan agar ke depan dapat menyusun kegiatan Pengabdian kepada Masyarakat yang lebih baik dan bermanfaat.

\section{Daftar Pustaka}

Alam H, Syamsul. (2015). Membangun Perpustakaan Desa menjadi Peletak Dasar Lahirnya Budaya Baca Masyarakat di Pedesaan. Jupiter Vol. XIV No. 2 Tahun 2015.

Bondar, A. (2019). Analisis pembangunan bidang perpustakaan terhadap peningkatan kualitas manusia dan penurunan kemiskinan. Media Pustakawan, 26(2), 72-80.

Darmawan, H. (2019). Sosialisasi Perpustakaan Berbasis Inklusi Sosial. Retrieved March 28, 2020, from https:/ / www.perpusnas.go.id/newsdetail.php?lang=id\&id=190328065053IwHcN3x $9-8 \mathrm{C}$

Irsan. (2019). Transformasi Perpustakaan Umum Sebagai Ruang Pelibatan Masyarakat (Studi Kasus: Dinas Perpustakaan Umum dan Kearsipan Kabupaten Enrekang ). Media Pustakawan, 26(3), 245-253.

Utami, D., \& Prasetyo, W. D. (2019). Perpustakaan berbasis inklusi sosial untuk pembangunan sosial-ekonomi masyarakat. Visi Pustaka, 21(1), 29-35. 